\title{
Analysing Indonesian Air Connectivity Period of 2006 - 2016
}

\author{
Prayoga Nugraha \\ Airport Authority Office Region - X, Merauke, INDONESIA \\ kotaksurat_yoga@yahoo.com
}

\begin{abstract}
As an emerging country, Indonesia needs to cope up with recent global development. One of those pivotal elements is arguably the air connection. However, no studies have been found examining Indonesian air connectivity in detail. Deriving from such a situation, this study attempts to analysis the connectivity levels of Indonesia through the period of 2006 and 2016 . The study uses the Netscan formulae which entail three elements, namely direct, indirect and hub connectivity. It has been noted that Indonesian connectivity has significantly increased by doubling in size. As a result, the country is relatively well connected in domestic level. Furthermore, many global destinations can be reached thanks to onward connections offered by international gateways with an exception toward Latin America and Central Asia. A contra-productive decision of government concerning designation of main international gateways is also outlined. As these airports mainly located in western part yet their growth is comparatively mature than those are in the eastern part or smaller regions. In terms of airport network, Indonesian airports have greatly raised their hub connectivity by nearly three times. However, these airports have barely been utilised as an intermediate stop for international flights. Finally, this study recommends suggestions to improve the connectivity level from available literature.
\end{abstract}

Keywords: Air connection, connectivity unit, international gateways, Netscan.

\section{INTRODUCTION}

In recent air transport literature, connectivity has surfaced to become an important variable notably as a key driver to unlock area potential, attract investment, human capital and tourism (Morphet \& Bottini, 2016), spurring globalisation (Hummels, 2007), and closely related to the productivity and ultimately bring prosperity (ACI, 2014). In fact, various methodologies have been conducted to analyse the connectivity level of specific market analyze the connectivity level of specific market (Veldhuis, 1997), regions (Malighetti, Paleari, and Redondi, 2008), or further, against global environment (Burghouwt and Redondi, 2009; Arvis and Shepherd, 2011; Allroggen and Malina, 2015).

In the same way, Indonesia has also gained consideration as one of the emerging economies and arguably puts the necessity to depict country's current connectivity performance. However, no comprehensive studies are found concerning Indonesian air connectivity (Nugraha, 2016). This study sets out to draw from a combination of both backgrounds. The growing importance of air connectivity and the state of Indonesia as an emerging country, have become the main motive of this study. Therefore, this study attempts to fill the void and aiming to explore the connectivity development and to further enrich the existing literature. Noted that pioneers' flights are not taken into consideration, and it is beyond the scope of this study to examine air freight links.

\section{METHODOLOGY AND DATA}

Since the emergence of hub-and-spoke network strategy, many academics have attempted to gauge the connectivity in an air transport network, which takes into account both direct and indirect flights. The most frequently used methods with recent indexes have been surfacing in the literature, such as: The Netscan model (Veldhuis,1997; De Witt et al., 2009), Weighted Number of Connections (Burghouwt \& de Witt, 2005), Bootsma Connectivity (Bootsma, 1997 cited by Burghouwt and Redondi, 2009), Weighted Connectivity Number (DaneSi, 2006 cited by Burghouwt and Redondi, 2009), Doganis and Dennis Connectivity (Dennis, 1994), Shortest Path Length (Malighetti et al., 2008), Global Connectivity Index (Allogren et al., 2015), Air Conectivity Index (Arvis and Shepherd, 2011). In summary, although each method has similarities and differences, all are still relevant to depict the nature of today's connectivity literature, which is the accessibility and dependent on the research intention to portray the connectivity magnitude.

The Netscan formulae have exclusively been employed to catch the purpose of this study as they considerably fit with the data source and provides an in-depth analysis as proven by many studies. Moreover, the 
Airport Commission International (ACI) has also adopted the formulae in describing the European connectivity performance. The formulae were first designed by Veldhuis in (1997) with the aim to measure the degree of accessibility an airport offered and its competitiveness by quantifying the connectivity value through direct and indirect flights. Figure 1 illustrates the typology of each connectivity from airport a viewpoint. In short, there are three standard elements in this formulae; they are direct, indirect and hub connectivity. Direct connectivity is defined as a flight in a particular route without transfer, while indirect connectivity contains one stop during passenger's journey. As for hub connectivity, it is a measure to determine airport level as an intermediate stop for connecting flights.

The Netscan formulae ascribe connection's value, ranging from zero to one. The value is taken as a weighting factor concerning the quality of a flight, both direct and indirect flights. It is then multiplied by the number of viable connections offered on that specific route and form the so-called Connectivity Unit ( $C N U$ ). All the $C N U$ s are summarised with respect to an airport's route to portray its accessibility. The value of one is always rewarded to direct flights as this type regarded as the most satisfying option from the passenger's perspective. However, an indirect flight is perceived as less satisfying; requiring not only additional time at the connecting airport but also inherently risky (e.g. losing baggage or missing the connecting flight); thus the value is always attributed below one. Moreover, if the total travel time exceeds a certain threshold, the quality of that particular indirect flights equals zero. Reflecting indirect flight's value constantly lower than one. Therefore, the quantification of such flight type is calculated as follows:

$$
N S T=\{(40+0.068 * \mathrm{gcd})\} / 60
$$

$$
M A X T=\{3-(0.075 * N S T)\}^{*} N S T
$$

$$
\begin{aligned}
& P T T=F L Y+\{(3-(0.075 * N S T)\} * T R F \\
& Q U A L=1-\{(P T T-N S T) /(M A X T-N S T)\} \\
& C N U=Q U A L * F R E Q
\end{aligned}
$$

where NST is non-stop travel time (hours), TRF is transfer time (hours), gcd is great-circle distance (kilometres), $Q U A L$ is quality index of a connection, $M A X T$ is maximum perceived travel time (hours), $C N U$ is number of connectivity units, $P T T$ is perceived travel time (hours), FREQ is number of viable connection, and FLY is flying time (hours).

To gain a comprehensive result, this study utilises two different minimum connecting times (MCTs). On the domestic routes, 45 minutes has been used as a threshold, whilst 60 minutes is used for international orientation. The difference in acceptance levels stems as international flights need extra time to anticipate rescreening processes in the terminal. Necessary to note, as the propensity to fly has increased along with the demand for greater comfort, thus the formulae consider one stop as a feasible threshold for a connecting flight. However, sometimes airlines mislead the flight meaning by advertising it as "direct" but in a reality, it stops for various reasons. Therefore, to provide accurate information a different adaption is used for each flight type. For direct flights, it always considers a "true" flight without breaks, while two stops are used as the limit for compromising the confusion in an indirect scheme.

The primary data are retrieved from the Official Airline Guide (OAG) for the second week of June during 2006 to 2016. The data consists of flight schedule information, such as operating carriers, origin, destination, flight frequency, journey time, departure and arrival time. It also includes airport related information such as connecting times, as well as the distance between the airports.

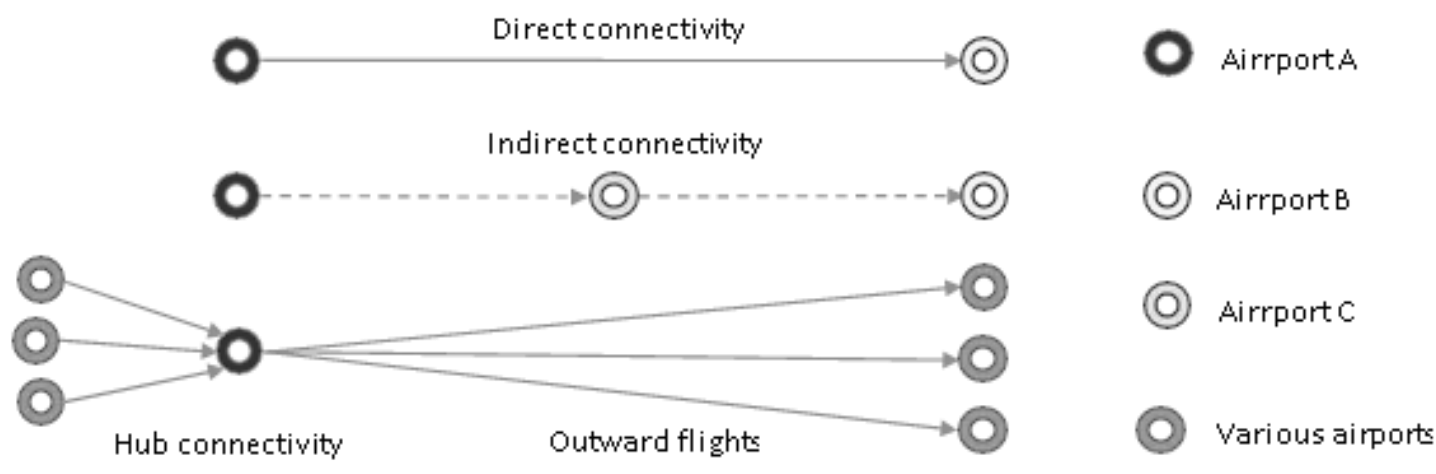

Figure 1. Connection categories from the perspective of airport A (De Wit, et al., 2009) 


\section{OVERVIEW OF INDONESIAN AIRPORT ACCESSIBILITY}

This section analyses the dynamic changes of Indonesian airports accessibility and its underlying causes and impacts from various perspectives.

\subsection{Direct and Indirect Connectivity}

Through the main period of analysis (Figure 2), overall, the connectivity level of the Indonesian airport system has significantly increased from $12,000 \mathrm{CNU}$ reaching $27,500 \mathrm{CNU}$ or approximately more than double its size in 2006. The number derives from the sum of direct and indirect connectivity which simultaneously shows a substantial increment. Direct connectivity boosted from about 7,500 $C N U$ to $15,800 C N U$, showing an increase of 113 percent and thus directly affecting indirect connections, as demonstrated by a remarkable 160 percent of growth: rising from 4,500 $C N U$ to $11,800 C N U$. However, between the period of 2008 and 2009 , connectivity level performance had slightly decelerated due to the massive slowdown in the global economy, which also distressed Indonesian market.

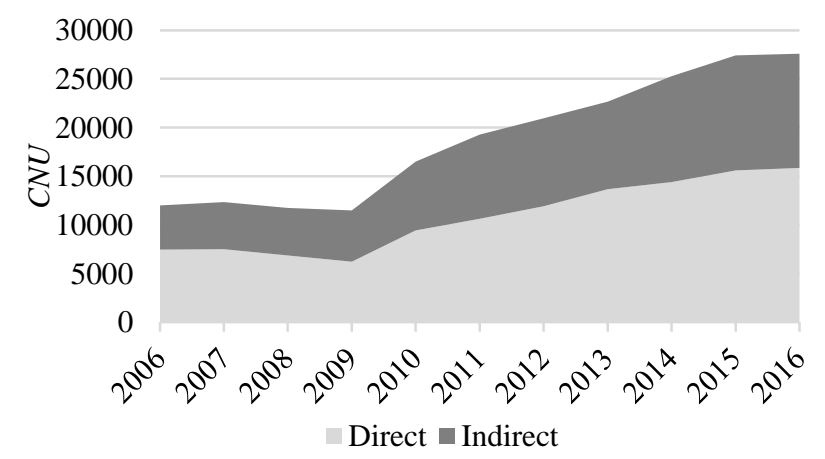

Figure 2. Total Connectivity Performance

After the recession, the connectivity performance bounced back by nearly half, rising comparably with the preceding year. This exceptional performance resulted from a combination of two fundamental elements; the increment of passenger purchasing power and the emergence of the low-cost carrier (LCC) that offers lower airfare had significantly attracts more air travellers (Kompas, 2010).

\subsection{Regional Direct Connectivity}

Departing from the previous result, it is essential to break down the analysis into a smaller scale for obtaining an in depth observation. Figure 3 shows a region's capability in terms of directly connecting to other destinations. Overall, all regions have improved greatly their connectivity performance with an outstanding performance in Nusa Tenggara, Maluku and Papua. As a result, the country is well connected domestically. However, this might expose a contra- productive policy concerning the designation of main international airports which mainly located in the western part (Kualanamu, Soekarno-Hatta, and Juanda). On one hand developing markets have been seen in eastern parts, while on the other hand, they are remote from direct international links.

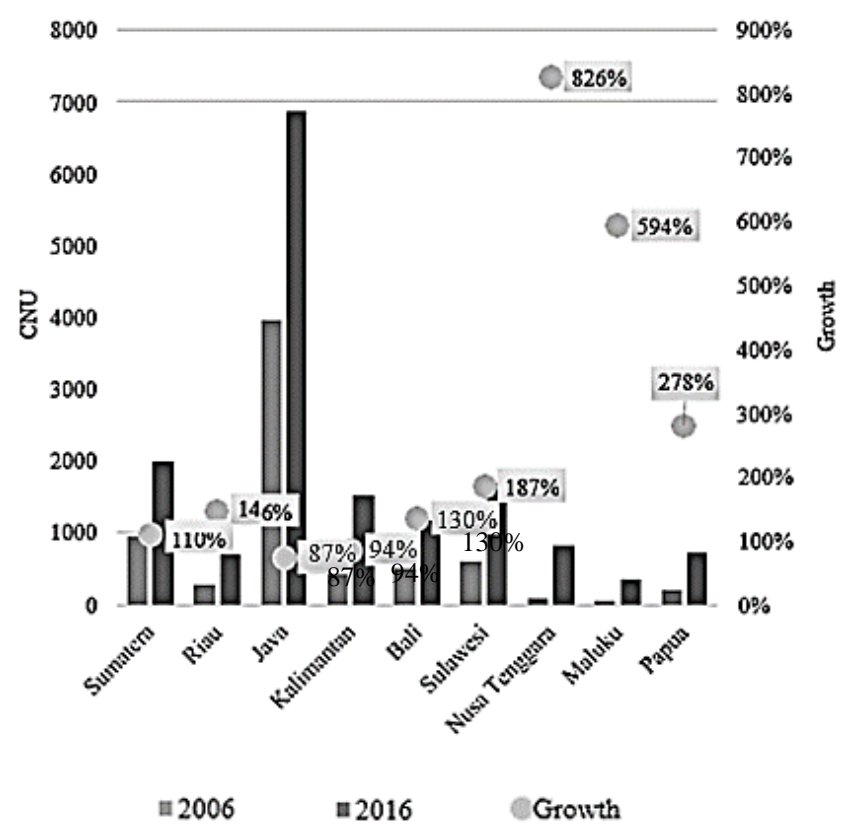

Figure 3. Regional Direct Connectivity Performance

\subsection{Direct Destination Market Analysis}

Having presented overall Indonesian connectivity performance, the following analysis is exhibited related to destination market offered from Indonesian airports. Southeast Asia, as the closest region has consistently become the most prominent destination followed by East Asia, Australia and Middle East (Table 1). The result reflects a linear relationship in trading between Indonesia and respective regions, with exception to the Middle East (SI, 2015). However, Southeast Asia growth is the lowest when compared to adjacent regions such as Australia and East Asia. In fact, an extraordinary growth is seen by the former. The growth of Australia-oriented flights has notably emerged by rising more than five times and might indicate a potentially close interdependence between two countries. The operation of Jetstar, one of the country's LCCs, has also facilitated the stimulation of the market. As for the latter, the rising is mainly associated with a close economic relationship, specifically with Japan and China (both account for 20 percent of the total export in 2014).

Similar to Australia, an extraordinary increase is also seen in the Middle East which primarily arises from the success of Gulf carrier's infiltration to connect regions worldwide from their respective hubs. Turning to South Asia, only Sri Lanka represents the region, thanks to 
their low- fare leisure carrier, Mihin-Lanka, that consistently serves the market. An improvement is seen at destinations towards the European contingent thanks to the connections brought by KLM and Turkish Airlines.

Table 1. International Destinations Distribution $(C N U)$

\begin{tabular}{|c|c|c|c|c|c|c|c|c|}
\hline$\overline{\text { Year }}$ & Southeast Asia & East Asia & Australia & Middle East & South Asia & Europe & America & Africa \\
\hline 2006 & 561 & 126 & 34 & 27 & - & - & - & - \\
\hline 2007 & 597 & 127 & 41 & 21 & - & - & - & - \\
\hline 2008 & 724 & 142 & 46 & 21 & - & - & - & - \\
\hline 2009 & 820 & 170 & 83 & 38 & - & 1 & - & - \\
\hline 2010 & 879 & 184 & 107 & 64 & - & 1 & - & - \\
\hline 2011 & 974 & 214 & 144 & 64 & 3 & - & - & - \\
\hline 2012 & 1,075 & 238 & 139 & 73 & 4 & 1 & - & - \\
\hline 2013 & 1,198 & 221 & 134 & 79 & 9 & - & - & - \\
\hline 2014 & 1,259 & 274 & 185 & 90 & 9 & 17 & - & - \\
\hline 2015 & 1,234 & 265 & 156 & 114 & 7 & 12 & - & - \\
\hline 2016 & 1,120 & 282 & 174 & 122 & 5 & 10 & - & - \\
\hline$\triangle \%(06-16)$ & $100 \%$ & $124 \%$ & $412 \%$ & $370 \%$ & - & - & - & - \\
\hline
\end{tabular}

Table 2. Flight Frequency per Airline Type

\begin{tabular}{|c|c|c|c|c|c|}
\hline \multirow[t]{2}{*}{ Year } & \multicolumn{2}{|c|}{ Local Carrier (LC) } & \multirow[t]{2}{*}{ LC Share } & \multirow{2}{*}{$\begin{array}{l}\text { International } \\
\text { Carrier (IC) }\end{array}$} & \multirow[t]{2}{*}{ IC Share } \\
\hline & $\overline{\mathrm{LCC}}$ & Non-LCC & & & \\
\hline 2006 & 1,663 & 5,258 & $92.9 \%$ & 526 & $7.1 \%$ \\
\hline 2007 & 1,595 & 5,391 & $92.9 \%$ & 534 & $7.1 \%$ \\
\hline 2008 & 1,835 & 4,441 & $91.4 \%$ & 592 & $8.6 \%$ \\
\hline 2009 & 205 & 3,475 & $84.1 \%$ & 697 & $15.9 \%$ \\
\hline 2010 & 3,301 & 5,419 & $92.5 \%$ & 705 & $7.5 \%$ \\
\hline 2011 & 4,024 & 5,856 & $92.8 \%$ & 764 & $7.2 \%$ \\
\hline 2012 & 4,847 & 6,237 & $92.9 \%$ & 841 & $7.1 \%$ \\
\hline 2013 & 7,102 & 5,739 & $93.8 \%$ & 848 & $6.2 \%$ \\
\hline 2014 & 7,566 & 5,812 & $92.8 \%$ & 1,040 & $7.2 \%$ \\
\hline 2015 & 7,684 & 6,848 & $93.1 \%$ & 1,085 & $6.9 \%$ \\
\hline 2016 & 6,802 & 8,005 & $93.3 \%$ & 1,058 & $6.7 \%$ \\
\hline$\triangle \%(06-16)$ & $309 \%$ & $52 \%$ & & $101 \%$ & \\
\hline
\end{tabular}

Although trading between Indonesia and America specifically with the United States (US) have been economically significant, however, due to safety reasons all Indonesian carriers has been banned since 2007 to fly over US's skies. This loss arguably decelerated Indonesian economic growth, particularly towards emerging countries in Latin America. On August 2016, the long-awaited cleareance finally has been granted to Indonesian airlines by the Federal Aviation Administration (FAA); airline safety level has been upgraded to "Category 1" (BBCNews, 2016).

\subsection{Air Carrier Analysis}

This section examines airline performance in providing direct connections. Air carriers are divided into three groups LCC, non-LCC (both are accounted as local carriers) and international carriers. Overall, this figure proves how conservatively air links distribute subject to carrier nationality. Although International carriers have escalated their operations by doubling their service (Table 2), their current share only accounts for less than seven percent, compared to local carriers which consistently hold the majority share. Furthermore, the table shows how progressively LCCs have developed during the last decade by intensifying their connectivity four times, compared with non-LCCs which were only able to increase about fifty percent. This circumstance demonstrates how remarkable lower fares are appreciated by the Indonesian traveller, particularly by an extreme performance from Lion Group (Lion and Wings Air). 


\subsection{International Gateways}

As globalisation has been recently inevitable, therefore it is crucial to outline airports in which various parts of the world can be reached thanks to their onward connections. Table 3 describes the top gateways, subject to specific global regions. The domestic market is not included, in order to allow a fair assessment between gateways. It can be concluded how significantly Changi (SIN) has connected the Indonesian market globally, particularly to East Asia, South Asia and Western Europe. Regarding the first orientation-mentioned, results show that although there is a growing competition between East Asian hubs in connecting the traveller to their region, SIN is still considerably dominant in the view of the Indonesia air network.

Turning to South Asia orientation, besides SIN, airports which have consistently offered the connections are Kuala-Lumpur (KUL) and Suvarnabhumi-Thailand (BKK). Therefore, there may be competition between both airports toward this particular route. For Middle East orientation, Soekarno-Hatta (CGK) always sits first, due to its importance as a stopping point for connecting locals regularly to holy cities in Saudi Arabia. However, Gulf hubs started to claim their territory, specifically Doha $(\mathrm{DOH})$ which has delivered an outstanding performance. This situation cannot be separated from their brand-new airport, which began operation in 2014. However, unreliable connections are found in Central Asia with no particular gateway which may be looked in two ways. On one hand, it might be a loss as it is crucial for Indonesia as an emerging country to have reliable access worldwide. On the other hand, it might give an impression of less economic interest between both parties.
Regarding European connections particularly in the west, there is a growing competition between SIN and Schipol (AMS). The latter has transformed into a fundamental stop point in reaching Europe by overlapping Frankfurt (FRA). Moreover, Gulf hubs have started to intensify the competition. Turning to Central Europe, most of the period connections have been dominated by European hubs, but surprisingly DOH is currently offering more connections. In fact, it is shifting Istanbul (IST) and AMS from the top, although both have shown a decent increment recently.

Concerning destinations towards America, particularly to the north, competition comprising particular regions' hubs is identified. It is noted that the route has been dominated by East Asia hubs, with the only SIN as an outsider. Interestingly, none of the China hubs are found on the list and gives an impression of airport's regional orientation. Moreover, it signifies the inefficiency route's development among Skyteam members (Garuda and three China's Airlines). Shifting to the south, there are now more options with the emergence of Dubai (DXB) as they offer more connections toward the region. However, it has been identified that the quality of all the connections are below 0.5 and would be seen as an inconvenience routes. The case elaborated from the fact that flight paths are not taking a relative inline corridor towards the region. As for Africa destinations, there has been a change in an important connector from SIN shifting to Gulf hubs. In fact, the competition between Gulf hubs seems tight in this route. Concerning the Australia and Oceania direction, Sydney (SYD) has successfully secured their own territory by having a significant margin to its competitors. 
Table 3. International Gateways Based on Global Destinations (CNU)

\begin{tabular}{|c|c|c|c|c|c|c|c|c|c|c|c|c|c|c|c|c|c|c|c|c|c|c|}
\hline \multirow{2}{*}{$\begin{array}{l}\text { Destination } \\
\text { Gateways }\end{array}$} & \multicolumn{2}{|c|}{$\begin{array}{l}\text { Southeast } \\
\text { Asia }\end{array}$} & \multicolumn{2}{|c|}{ East Asia } & \multicolumn{2}{|c|}{$\begin{array}{l}\text { Middle } \\
\text { East }\end{array}$} & \multicolumn{2}{|c|}{$\begin{array}{l}\text { Australia \& } \\
\text { Oceania }\end{array}$} & \multicolumn{2}{|c|}{$\begin{array}{l}\text { Western } \\
\text { Europe }\end{array}$} & \multicolumn{2}{|c|}{ South Asia } & \multicolumn{2}{|c|}{$\begin{array}{l}\text { North } \\
\text { America }\end{array}$} & \multicolumn{2}{|l|}{ Africa } & \multicolumn{2}{|c|}{$\begin{array}{l}\text { Central } \\
\text { Europe }\end{array}$} & \multicolumn{2}{|c|}{$\begin{array}{l}\text { Latin } \\
\text { America }\end{array}$} & \multicolumn{2}{|c|}{$\begin{array}{l}\text { Central } \\
\text { Asia }\end{array}$} \\
\hline & 2006 & & & & & & & & & & & & & & & & & & & & & \\
\hline & SIN & 81 & SIN & 253 & CGK & 220 & SIN & 132 & SIN & 481 & SIN & 127 & TPE & 96 & SIN & 28 & FRA & 8 & SYD & 1 & KUL & 1 \\
\hline & KUL & 37 & HKG & 198 & SIN & 86 & SYD & 85 & FRA & 179 & KUL & 25 & SIN & 90 & KUL & 8 & AMS & 5 & & & & \\
\hline & CGK & 32 & CAN & 109 & JED & 35 & DPS & 27 & AMS & 166 & BKK & 14 & $\mathrm{HKG}$ & 81 & DXB & 7 & SIN & 3 & & & & \\
\hline \multirow[t]{4}{*}{ Gateways } & 2008 & & & & & & & & & & & & & & & & & & & & & \\
\hline & SIN & 75 & SIN & 285 & CGK & 215 & SYD & 135 & SIN & 653 & SIN & 136 & TPE & 127 & SIN & 35 & FRA & 9 & SYD & 2 & KUL & 1 \\
\hline & CGK & 46 & HKG & 179 & SIN & 112 & SIN & 116 & FRA & 180 & KUL & 26 & HKG & 92 & DOH & 19 & SIN & 8 & & & & \\
\hline & KUL & 43 & $\mathrm{ICN}$ & 129 & KUL & 47 & MEL & 24 & AMS & 167 & BKK & 17 & SIN & 75 & KUL & 11 & AMS & 6 & & & & \\
\hline \multirow[t]{4}{*}{ Gateways } & 2010 & & & & & & & & & & & & & & & & & & & & & \\
\hline & CGK & 59 & SIN & 237 & CGK & 668 & SYD & 170 & SIN & 535 & SIN & 102 & TPE & 113 & DXB & 46 & AMS & 21 & SYD & 5 & KUL & 2 \\
\hline & SIN & 58 & HKG & 218 & SIN & 111 & SIN & 96 & AMS & 411 & KUL & 47 & HKG & 103 & SIN & 25 & SIN & 12 & AMS & 4 & BKK & 1 \\
\hline & KUL & 54 & ICN & 203 & DXB & 89 & MEL & 67 & CGK & 198 & BKK & 22 & ICN & 69 & DOH & 24 & FRA & 9 & PVG & 1 & & \\
\hline \multirow[t]{4}{*}{ Gateways } & 2012 & & & & & & & & & & & & & & & & & & & & & \\
\hline & CGK & 91 & SIN & 393 & CGK & 770 & SYD & 216 & SIN & 680 & SIN & 137 & $\mathrm{HKG}$ & 168 & DON & 38 & IST & 32 & SYD & 8 & KUL & 2 \\
\hline & KUL & 72 & HKG & 389 & SIN & 129 & SINB & 116 & AMS & 420 & KUL & 53 & TPE & 145 & JED & 32 & AS & 16 & DXB & 4 & BKK & 1 \\
\hline & SIN & 65 & CGK & 250 & DXB & 89 & MEL & 90 & CGK & 169 & BKK & 42 & ICN & 106 & DXB & 31 & $\mathrm{DOH}$ & 15 & PVG & 3 & & \\
\hline \multirow[t]{4}{*}{ Gateways } & 2014 & & & & & & & & & & & & & & & & & & & & & \\
\hline & SIN & 92 & SIN & 453 & CGK & 836 & SYD & 221 & SIN & 754 & SIN & 178 & NRT & 189 & SIN & 55 & IST & 33 & SYD & 6 & AUH & 1 \\
\hline & CGK & 87 & CGK & 355 & SIN & 159 & SIN & 130 & AMS & 491 & KUL & 93 & ICN & 155 & JED & 42 & SIN & 23 & DXB & 4 & & \\
\hline & CGK & 80 & HKG & 325 & JED & 108 & MEL & 122 & CGK & 201 & BKK & 26 & HKG & 150 & DXB & 36 & AMS & 21 & AMS & 4 & & \\
\hline \multirow[t]{4}{*}{ Gateways } & 2016 & & & & & & & & & & & & & & & & & & & & & \\
\hline & SIM & 115 & SIN & 460 & CGK & 965 & SYD & 226 & SIN & 707 & SIN & 198 & NRT & 250 & DOH & 65 & $\mathrm{DOH}$ & 57 & DXB & 6 & IST & 1 \\
\hline & CGK & 80 & CAN & 359 & $\mathrm{DOH}$ & 252 & SIN & 118 & AMS & 531 & KUL & 101 & HKG & 160 & JED & 61 & IST & 50 & SYD & 5 & BKK & 1 \\
\hline & KUL & 63 & HKG & 340 & SIN & 182 & MEL & 95 & DXB & 281 & BKK & 33 & ICN & 148 & DXB & 59 & AMS & 31 & AMS & 3 & & \\
\hline
\end{tabular}




\section{OVERVIEW OF HUB CONNECTIVITY}

This section presents hub connectivity performance of Indonesian airport and a successive subsection is attributed concerning OD markets via Indonesian airports. During the analysed period, the airport system has productively optimised their network by increasing in number three-fold; it raises from 2,000 $C N U$ to 6,000 $C N U$ (Figure 4). This context indicates how efficiently Indonesian airports have developed to cope up with the growth of total connection that accounts 2.3 times. However, since 2014, the score has stagnated and in fact, slightly decreased this year. The shifting of the network strategy adopted by AirAsia and Lion becomes the main factor; they have become prominent in using point-to-point strategy. Moreover, it has been verified that the temporary closure of 127 routes by Lion on June 2016 has greatly decreased overall hub connectivity performance (Detiknews, 2016).

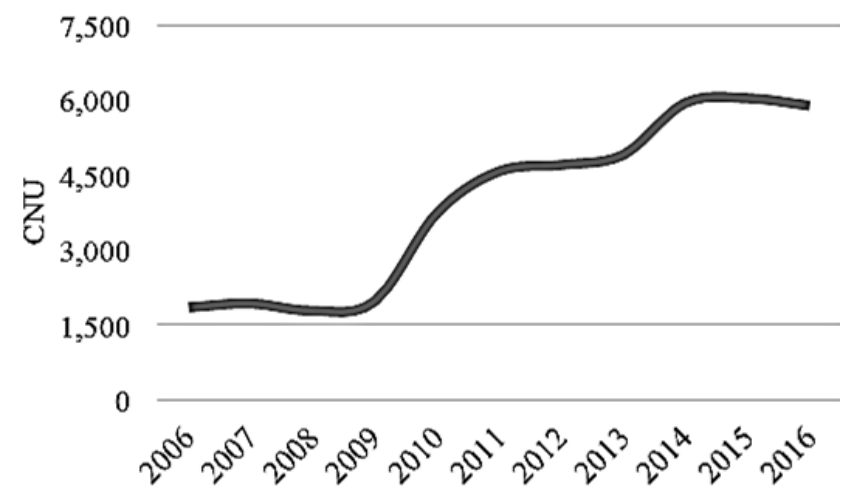

Figure 4. Hub connectivity performance.

\section{ORIGIN-DESTINATION (OD) ANALYSIS}

Table 4 provides an analysis, observing top routes via Indonesian airports together with respective carriers. Overall, there have been changes to the domain OD market from local centrist to more international orientation (marked with yellow and grey block). However, the importance of Indonesian hubs as gateways from the international perspective is relatively insignificant as only CGK seen as an adequate transfer point for the majority international routes. In fact, these connections are mainly generated from domestic inward flights. Moreover, no international OD market can be found in today's market. Only connections that partially connect through domestic routes play a significant part, particularly to the Middle East. This result indicates that the joining of Garuda (GA) to Skyteam in 2014, has not been positively affecting local airports as most connecting flights are still operated by GA. Come to second is Sultan-Hasanuddin (UPG). Although marginal, its centre position as a local hub is important specifically for connecting eastern and western part.
Moreover, the table remarks in which areas the two largest airlines are dominant; Garuda concentrates in CGK while Lion (JT) utilises UPG.

\section{IMPROVING CONNECTIVITY PERFORMANCE}

This section endeavours to provide alternatives for improving the connectivity performance from available literature. In reality, providing direct flights should be the first option. However, such connections might face obstacles deriving from economic or political factors. Therefore, identifying and connecting the network via certain gateways that offer more reliable connection can be a critical solution. Additionally, an evaluation concerning Indonesian alternative hubs is carried out in the successive chapter.

\subsection{Potential Valuable Gateways}

As mentioned in preceding result, not all global destinations have a reliable connection, particularly to Latin America and Central Asia. This section attempts to address such issues by identifying gateways that have better access toward those destinations. The measurement considers all connections towards the regions and identifies a discrepancy which is not found in the existing result.

Table 5 provides alternative routes towards Latin America. It has been identified that Auckland (AKL) and Narita (NRT) are offering regular connecting flights. Basically, the result is taken from the existing indirect connections. Nevertheless, the quality indices have been zero, due to the unsuitable longer waiting time. Therefore, minimizing the connecting time at both airports is crucial. Based on the calculation, 120 minutes is a relevant threshold to obtain considerable quality connecting value. As the existing first leg carriers do not belong to the government, GA then is suggested to operate the route or advocate JT to shift their departure time. As at Narita, Garuda has an advantage by having Aeromexico (AM) as their counterpart carrier (both are Skyteam members). Nevertheless, the proposition has drawbacks as both would technically be operated during the inconvenience time.

Turning to Central Asia, a more straightforward approach is suggested by identifying airports which simultaneously offers frequent flights and locates on a relevant flight corridor. It has been verified that Urumqi-China can be a potential gateway as it serves 43 flights weekly. Thanks to the alliance coordination, GA could utilise China-Southern's network, which is one of the airport's main costumers. 
Table 4. Top OD Markets via Indonesian Hubs

\begin{tabular}{|c|c|c|c|c|c|c|c|c|c|c|c|c|c|c|c|c|}
\hline \multirow[t]{2}{*}{ Rank } & \multicolumn{4}{|l|}{2006} & \multicolumn{4}{|l|}{2010} & \multicolumn{4}{|l|}{2014} & \multicolumn{4}{|l|}{2016} \\
\hline & OD market & & $\begin{array}{l}\text { Main } \\
\text { hub }\end{array}$ & $\begin{array}{l}\text { Main } \\
\text { flight } \\
\text { combo }\end{array}$ & OD market & & $\begin{array}{l}\text { Main } \\
\text { hub }\end{array}$ & $\begin{array}{l}\text { Main } \\
\text { flight } \\
\text { combo }\end{array}$ & OD market & & $\begin{array}{l}\text { Main } \\
\text { hub }\end{array}$ & $\begin{array}{l}\text { Main } \\
\text { flight } \\
\text { combo }\end{array}$ & OD market & & $\begin{array}{l}\text { Main } \\
\text { hub }\end{array}$ & $\begin{array}{l}\text { Main } \\
\text { flight } \\
\text { combo }\end{array}$ \\
\hline 1 & SUB-MES & 39 & CGK & KI-KI & MES-SUB & 41 & CGK & GA-GA & SUB-KNO & 46 & CGK & JT-JT & JED-SUB & 39 & CGK & GA-GA \\
\hline 2 & MES-SUB & 25 & CGK & GA-GA & MES-DPS & 39 & CGK & JT-JT & UPG-KNO & 45 & CGK & JT-JT & UPG-KNO & 36 & CGK & GA-GA \\
\hline 3 & DPS-MES & 20 & CGK & GA-GA & JED-SUB & 36 & CGK & GA-GA & SUB-DJJ & 43 & UPG & JT-JT & SUB-JED & 35 & CGK & GA-GA \\
\hline 4 & MES-DPS & 19 & CGK & GA-GA & SUB-JED & 32 & CGK & GA-GA & CGK-DJJ & 41 & UPG & JT-IW & DJJ-CGK & 34 & UPG & JT-JT \\
\hline 5 & MES-JOG & 16 & CGK & GA-GA & SUB-JED & 31 & CGK & JT-JT & SUB-JED & 38 & CGK & GA-GA & KNO-UPG & 31 & CGK & GA-GA \\
\hline 6 & UPG-MES & 16 & CGK & GA-MH & AMQ-CGK & 29 & UPG & JT-JT & JED-SUB & 36 & CGK & GA-GA & AMQ-CGK & 30 & UPG & ID-ID \\
\hline 7 & SUB-JED & 14 & CGK & GA-MH & DPS-DXB & 28 & CGK & GA-GA & DPS-KNO & 35 & CGK & JT-JT & SUB-DJJ & 29 & UPG & JT-JT \\
\hline 8 & JOG-MES & 13 & CGK & KI-KI & JOG-JED & 25 & CGK & GA-GA & KNO-UPG & 35 & CGK & JT-JT & UPG-JED & 28 & CGK & GA-GA \\
\hline 9 & SIN-SYD & 13 & CGK & SQ-QF & SUB-DXB & 25 & CGK & GA-EK & KNO-SUB & 34 & CGK & JT-JT & SUB-DOH & 28 & CGK & GA-QR \\
\hline 10 & FRA-SIN & 13 & CGK & LH-SQ & UPG-MES & 24 & CGK & JT-JT & DJJ-CGK & 32 & UPG & SJ-SJ & JED-JOG & 28 & CGK & GA-GA \\
\hline 11 & AMQ-CGK & 13 & UPG & JT-JT & JED-JOG & 24 & CGK & GA-GA & KNO-JOG & 30 & CGK & JT-JT & DPS-DOH & 28 & CGK & GA-QR \\
\hline 12 & AMS-SUB & 12 & CGK & KL-GA & DXB-SUB & 24 & CGK & GA-GA & JED-JOG & 29 & CGK & GA-GA & SUB-KNO & 26 & CGK & GA-GA \\
\hline 13 & SUB-AMS & 11 & CGK & GA-KL & SUB-MES & 21 & CGK & JT-JT & DPS-JED & 26 & CGK & GA-GA & DOH-SUB & 25 & CGK & QR-GA \\
\hline 14 & SUB-PDG & 11 & CGK & 7P-7P & MES-UPG & 20 & CGK & JT-JT & DPS-DOH & 26 & CGK & GA-QR & JED-SRG & 25 & CGK & GA-GA \\
\hline 15 & UPG-PDG & 11 & CGK & JT-IW & SIN-AMS & 20 & CGK & GA-KL & JED-DPS & 26 & CGK & GA-GA & DPS-JED & 24 & CGK & GA-GA \\
\hline 16 & AMS-SIN & 10 & CGK & KL-SQ & SIN-SYD & 20 & CGK & SQ-QF & DPS-DXB & 25 & CGK & GA-EK & JED-DPS & 24 & CGK & GA-GA \\
\hline 17 & JED-SUB & 10 & CGK & GA-GA & DPS-AMS & 18 & CGK & GA-GA & JED-BPN & 24 & CGK & GA-GA & KNO-JOG & 24 & CGK & GA-GA \\
\hline 18 & RUH-SUB & 10 & CGK & GA-GA & UPG-DXB & 18 & CGK & GA-GA & UPG-JED & 24 & CGK & GA-GA & JED-UPG & 23 & CGK & GA-GA \\
\hline 19 & AMS-JOG & 10 & CGK & KL-GA & AMS-SIN & 17 & CGK & KL-SQ & KNO-DPS & 23 & CGK & JT-JT & JOG-DOH & 23 & CGK & GA-GA \\
\hline 20 & PDG-UPG & 10 & CGK & JT-JT & JED-DPS & 17 & CGK & GA-GA & JED-SRG & 22 & CGK & GA-GA & JOG-JED & 22 & CGK & GA-GA \\
\hline
\end{tabular}

: Domestic (D) Route

: International (I) Route

: Partial D/I

Table 5. Proposal Action for Enhancing Connectivity to Latin America

\begin{tabular}{|c|c|c|c|c|c|c|c|c|c|c|c|c|c|c|c|c|}
\hline No & Origin & Gateway & Dest & Itinerary & Opr1 & $\begin{array}{l}\text { Time1 } \\
\text { (minutes) }\end{array}$ & Opr2 & $\begin{array}{l}\text { Time2 } \\
\text { (minutes) }\end{array}$ & $\begin{array}{l}\text { Departure } \\
\text { time }\end{array}$ & $\begin{array}{l}\text { Arrival } \\
\text { Time }\end{array}$ & $\begin{array}{l}\text { Preposition } \\
\text { Departure } \\
\text { Time } 1\end{array}$ & $\begin{array}{l}\text { Arrival } \\
\text { Time } 1\end{array}$ & $\begin{array}{l}\text { Waiting } \\
\text { Gate } \\
\text { (minutes) }\end{array}$ & Quality & $\begin{array}{l}\text { Dept } \\
\text { Time } \\
2\end{array}$ & $\begin{array}{l}\text { Arrival } \\
\text { Time } 2\end{array}$ \\
\hline 1 & DPS & ARL & SCL & $\begin{array}{l}\text { DPS- } \\
\text { AKL- } \\
\text { SCL }\end{array}$ & $\mathrm{NZ}$ & 480 & LA & 680 & $17: 30$ & $05: 30$ & $04: 10$ & $16: 10$ & 120 & 0.60 & $18: 10$ & $13: 30$ \\
\hline 2 & CGK & NRT & MEX & $\begin{array}{l}\text { CKG- } \\
\text { NRT- } \\
\text { MEX }\end{array}$ & JT & 450 & $\mathrm{AM}$ & 765 & $21: 55$ & $07: 25$ & $00: 25$ & $12: 25$ & 120 & 0.65 & $14: 25$ & $13: 10$ \\
\hline
\end{tabular}




\subsection{Alternative Determinant Hubs}

As an emerging country, it is important for Indonesia to advertise its significance to the international environment. Moreover, by taking into account the ongoing and upcoming deregulated era should emphasise the need for advertising the Indonesian market globally. However, the result has shown that Indonesian airports have become less important as international hubs. Four proposals are suggested concerning such circumstances. From the analysis, it can be seen that connections are centralised towards the western part, specifically at Soekarno-Hatta. However, most connections are locally-oriented. Hence, shifting some local flights to the growing Halim (both located in Jakarta) is suggested to encourage international flights, particularly with the attraction of the brand new Ultimate T3 at Soekarno-Hatta. Alternatively, Ngurah Rai can be further developed into an important hub specifically for connecting the Northern Regionals towards Australia or vice versa. Geographically, Ngurah-Rai offers an in-line circuit. Moreover, it has an advantage as a global tourist destination, thus lifting the airport's advertisement. Similarly, Kualanamu could be beneficial for the airline's route development in connecting Australia and regions in Southeast Asia, South Asia and Africa. Moreover, it could stimulate the slow growth in the airport as slots have not been entirely utilised. Sultan-Hassanuddin has also the same bargaining power by having a strategic position, offering leisure attractions and on top of that, connections to the growing market in the eastern part of the country.

\section{CONCLUSIONS}

Through the analysis, Indonesian connectivity performance has significantly developed by increasing in number; it raises from $12,000 \mathrm{CNU}$ reaching nearly 27,000 CNU, comprising substantial performances of both direct and indirect connectivity. Fundamental reasons have been put forward to explain the circumstance which deriving from the emergence of LCC and country's economic growth. Regarding accessibility, the country has seen a major impact on indirect flight schemes that offer connections, not only to local destinations but also global destinations. Domestically, the country is relatively well connected. However, not all regions have direct international connections, particularly in the eastern part. Reflecting the government decision which only includes five airports as main international gateways, thus it can be concluded that the decision might be contraproductive, as high growth is seen on the east side. Concerning international destinations, the market is mainly dependent on international gateways, notably with the importance of Changi, followed by Narita and
Gulf hubs. Nonetheless, not all global regions can be reached by indirect connections specifically destinations to Central Asia and Latin America. Two approaches are suggested in order to fill the gap in reaching Latin America and Central Asia. For the former, connecting time at Auckland and Narita should be reduced by shifting the scheduled departing time earlier, while in the latter case, connecting in UrumqiChina is suggested. In terms of hub connectivity, Indonesian airports have increased their hub connectivity from $2,000 C N U$ to reach $6,000 C N U$. However, although the result is admirable, yet Indonesian airports have been barely utilised as an intermediate stop between international flights.

\section{REFERENCES}

ACI, 2014. Airport Industry Connectivity Report. [Online]

Available at: http://www.seo.nl/uploads/media/201545_ACI_EUROPE_Airport_Industry_Connectivity_R eport_2015.pdf

[Accessed 27 July 2016].

Allroggen, F., Wittman, M. \& Malina, R., 2015. How air transport connects the world - A new metric of air connectivity and its evolution between 1990 and 2012. Transportation Research Part E: Logistics and Transportation Review, Volume 80, pp. 184-201.

Arvis, J.-F. \& Shepherd, B., 2011. The air connectivity index. Policy Research Working Paper. [Online] Available at: http://developing-trade.com/wpcontent/uploads/2014/11/Working-Paper-DTC-2011$\underline{7 . p d f}$

[Accessed 27 July 2016].

BBCNews, 2016. Indonesian carriers cleared for US flights after nine-year ban. [Online] Available at: http://www.bbc.com/news/business$\underline{37091566}$

[Accessed 27 October 2016].

Burghouwt, G. \& de Wit, J., 2005. Temporal configurations of European airline networks. Journal of Air Transport Management, 11(3), pp. 185-198..

Burghouwt, G. \& Redondi, R., 2009. Connectivity in Air Transport Networks: An Assessment of Models and Applications.

[Online]

Available at:

https://www.researchgate.net/publication/257547529

Connectivity in Air Transport Networks An Asses

sment of Models and Applications

[Accessed 27 July 2016].

De Wit, J., Veldhuis, J., Burghouwt, G. \& Matsumoto, H., 2009. Competitive position of primary airports in 
the asia-pacific rim.. Pacific Economic Review, 14(5), pp. 639-650.

Dennis, N., 1994. Airline hub operations in Europe. Journal of Transport Geography, 2(4), pp. 219-233.

Detiknews, 2016. Kemenhub: 95 Rute Penerbangan Lion Air Berhenti Operasi Sebulan. [Online] Available at: http://news.detik.com/berita/3214101/kemenhub-95rute-penerbangan-lion-air-berhenti-operasi-sebulan [Accessed 31 July 2016].

Hummels, D., 2007. Transportation Costs and International Trade in the Second Era of Globalization. Journal of Economic Perspectives, 21(3), pp. 131-154.

Kompas, 2010. Garuda Indonesia Tambah 24 Pesawat Baru. [Online]

Available at: http://sains.kompas.com/read/2010/06/01/19463745/g aruda.indonesia.tambah.24.pesawat.baru [Accessed 27 Juny 2016].

Li, W., Miyoshi, C. \& Pagriari, K., 2012. Dual-hub network connectivity: An analysis of all Nippon Airways' use of Tokyo's Haneda and Narita airports. Journal of Air Transportation Management, Volume 23, pp. 12-16.

Malighetti, P., Paleari, S. \& Redondi,, R., 2008. Connectivity of the European airport network: "Self- help hubbing" and business implications. Journal of Air Transport Management, 14(2), pp. 53-65.

Morphet, H. \& Bottini, C., 2016. Why it matters and how to support growth. [Online] Available at: https://www.pwc.com/gx/en/capitalprojects-infrastructure/pdf/pwc-air-connectivity.pdf [Accessed 27 July 2016].

Nugraha, P., 2016. Analysing Indonesian Air Connectivity Period of 2006 - 2016, Yogyakarta: Master Thesis Report, Department of Civil and Environmental Engineering Department.

SI, 2015. Value of Export by Major Countries of Destination. [Online]

Available at:

https://www.bps.go.id/linkTabelStatis/view/id/1010 [Accessed 26 July 2016].

Suau-Sanchez, P. \& Burghouwt, G., 2012. Connectivity levels and the competitive position of Spanish airports and Iberia's network. Journal of Air Transport Management, 8(1), pp. 47-53.

Veldhuis, J., 1997. The competitive position of airline networks. Air Transport Management, 3(4), pp. 181188.

Veldhuis, N., 1997. Elementary education at Nippur. The lists of trees and wooden objects, Groningen. 